\title{
ESTUDO COMPARATIVO DAS CARACTERÍSTICAS DO TRATAMENTO TERMOQUÍMICO DE CEMENTAÇÃO SÓLIDA DE AÇO BAIXO CARBONO REALIZADO COM CARVÃO VEGETAL E COQUE DE BAIXA QUALIDADE METALÚRGICA*
}

\author{
Marta Barbosa Alvim ${ }^{1}$ \\ Rogério AntãoCardoso ${ }^{2}$ \\ Geraldo Lúcio de Faria ${ }^{3}$ \\ Paulo Sérgio Moreira ${ }^{4}$
}

\section{Resumo}

Amostras de aço baixo carbono (aço ABNT 1015) foram submetidas a tratamentos termoquímicos de cementação sólida fazendo-se uso de duas fontes distintas de carbono. Amostras do aço foram empacotadas em uma mistura de pós constituída pela fonte de carbono e cal hidratada e tratadas a $1000^{\circ} \mathrm{C}$ por 8 horas. As fontes avaliadas foram um tipo de carvão vegetal e uma remessa de coque de baixa qualidade metalúrgica. Realizados os tratamentos termoquímicos, as amostras cementadas foram devidamente caracterizadas por microscopia óptica e pela aplicação de ensaios de microdureza Vicker. Duas amostras cementadas foram, na sequência, submetidas a tratamentos térmicos de têmpera em água fazendo-se uso de duas temperaturas de austenitização $\left(860^{\circ} \mathrm{C}\right.$ e $\left.920^{\circ} \mathrm{C}\right)$ e também foram caracterizadas. Observou-se que no processo de cementação sólida, a peça cementada com carvão vegetal apresentou melhores resultados do que a cementada com coque de baixa qualidade. Com carvão vegetal, a camada cementada se mostrou mais espessa e homogênea em todo 0 perímetro das amostras. A amostra cementada com o coque de baixa qualidade apresentou, além da menor espessura de camada cementada, heterogeneidades grosseiras no perímetro da peça.

Palavras-chave:Cementação sólida; Coque; Carvão Vegetal; Microestrutura.

\section{A COMPARATIVE STUDY ABOUT THE CHARACTERISTICS OF SOLID CARBURIZING HEAT TREATMENTS ON A LOW CARBON STEEL PERFORMED WITH CHARCOAL AND LOW QUALITY METALLURGICAL COKE}

\begin{abstract}
Samples of low carbon steel (ABNT 1015 steel) were submitted to thermochemical treatments of solid carburizing using two different carbon sources. Samples of the steel were packaged in a powder mixture consisting of both carbon source and hydrated lime, submitted to $1000^{\circ} \mathrm{C}$ for 8 hours. The evaluated carbon sources were one type of charcoal and a low quality metallurgical coke. The carburized samples were characterized by optical microscopy and Vickers microhardness tests. Two carburized samples were, in sequence, submitted to a water quenching treatment using two different austenitizing temperatures $\left(860^{\circ} \mathrm{C}\right.$ and $\left.920^{\circ} \mathrm{C}\right)$ and were also characterized. It was observed that the specimens carburized with charcoal presented better results than the obtained with coke and hydrated lime. With charcoal, the carburized layer was thicker and homogeneous throughout the perimeter of the samples. The sample carburized with the low quality coke presented, in addition to the lower thickness of carburized layer, coarse heterogeneities on its perimeter.

Keywords: Solid carburizing; Coke; Charcoal; Microstructure.

1 Graduanda em Engenharia Metalúrgica, Departamento de Engenharia Metalúrgica e de Materiais (DEMET), Escola de Minas (EM), Universidade Federal de Ouro Preto (UFOP), Ouro Preto, MG, Brasil.

2 Graduando em Engenharia Metalúrgica, Departamento de Engenharia Metalúrgica e de Materiais (DEMET), Escola de Minas (EM), Universidade Federal de Ouro Preto (UFOP), Ouro Preto, MG, Brasil.

3 Físico, Doutor, Professor, DEMET, EM, UFOP, Ouro Preto, MG, Brasil.

4 Engenheiro Metalúrgico, Técnico Administrativo,DEMET, EM, UFOP Ouro Preto, MG, Brasil.
\end{abstract}




\section{INTRODUÇÃO}

Os tratamentos termoquímicos dos metais se enquadram em uma classe de tratamentos térmicos especiais que têm como objetivo principal promover 0 endurecimento superficial de componentes metálicos mantendo a tenacidade do núcleo da peça. Os efeitos principais destes tratamentos são aumentar a resistência ao desgaste, aumentar a resistência à corrosão em determinados meios agressivos, aumentar a resistência à deformação plástica localizada na superfície, aumentar a resistência à nucleação de trincas por fadiga entre outros [1-15].

Entre os tratamentos termoquímicos clássicos, os mais amplamente utilizados na indústria são: cementação (ou carbonetação), nitretação e boretação. O foco deste trabalho se dá sobre o tratamento termoquímico de cementação sólida. Este tratamento tem como objetivo promover a difusão controlada de carbono para a superfície de peças, aumentando a concentração deste elemento em uma determinada faixa de espessura. Este tratamento é comumente aplicado em aços com baixo teor de carbono, geralmente abaixo de $0,3 \%$ em peso. $O$ aumento da concentração de carbono em determinada região da peça promove um incremento de dureza pelo mecanismo de solução sólida, assim como por aumentar a fração de perlita na região, caso após a cementação, o aço seja normalizadoou recozido $[2,5,10,13]$.

A camada onde se verifica o aumento do teor de carbono em relação ao teor original da peça recebe o nome de camada cementada total, porém o aumento de dureza não é significativo em toda esta extensão. Via de regra, a dureza aumenta significativamente em uma faixa mais estreita, denominada camada cementada efetiva, ou seja, onde o efeito da cementação se mostra realmente efetivo na alteração de propriedades mecânicas da liga.

Como uma consequência imediata da cementação é o aumento do teor de carbono na superfície da peça, a temperabilidade desta região é fortemente afetada em relação à temperabilidade do aço base original [10,12]. Neste contexto, geralmente após a etapa de cementação, as peças são temperadas. Como a temperabilidade da camada cementada é maior do que a do núcleo da peça, nesta região pode ocorrer a formação preferencial de martensita e/ou bainita, constituintes que contribuem ainda mais para o aumento da dureza, enquanto em regiões mais centrais da peça, ainda com baixo teor de carbono e temperabilidade limitada, vão apresentar microestrutura majoritariamente ferrítica com pequena fração de perlita. Assim sendo, se obtém uma peça com elevada dureza superficial, porém com núcleo tenaz. Recomenda-se que após o tratamento térmico de têmpera seja feito um tratamento de revenimento para que se promova alívio de tensões na microestrutura $[1,15]$.

A cementação sólida consiste basicamente em empacotar, ou envelopar a amostra em uma caixa de aço com uma mistura sólida de fonte de carbono reativa e catalisadores. As fontes de carbono e o catalisador são pulverizados e misturados até que se obtenha uma mistura de pós homogênea. A esta mistura pode ser adicionado um óleo ligante, ou alcatrão. O fundo da caixa de aço é coberto com esta mistura (leito), em seguida a amostra de aço é colocada sobre este leito e é então coberta por outra porção da mistura. A caixa é então fechada e colocada em um forno pré-aquecido a uma temperatura acima de A3 para que a difusão do carbono aconteça no campo austenítico, onde a solubilidade dele é maior no aço. A temperatura e o tempo de tratamento influenciarão diretamente a espessura da camada cementada. 
Alguns estudos na literatura apontam que um ponto de interesse para desenvolvimento é testar combinações de diferentes fontes de carbono e de catalisadores com o objetivo de diminuir custo e aumentar a eficiência do tratamento $[10,11,13]$. Foi com este propósito que o presente trabalho foi desenvolvido. Buscouse avaliar a eficiência da cementação sólida em função da utilização de duas diferentes fontes de carbono: carvão vegetal proveniente de uma espécie de Eucalyptus e um coque de baixa qualidade metalúrgica. Amostras de aço baixo carbono foram cementadas a partir de misturas cementantes constituídas pelas duas fontes de carbono e as características das camadas cementadas foram avaliadas.

\section{MATERIAIS E MÉTODOS}

A metodologia científica aplicada no desenvolvimento deste trabalho foi dividida em quatro etapas, sendo elas: caracterização do estado de entrega do aço, preparação granulométrica dos pós de coque e carvão vegetal, caracterização dos pós de coque e carvão vegetal e realização dos tratamentos termoquímicos de cementação sólida. A Figura 1 é um fluxograma que resume as atividades acima citadas.

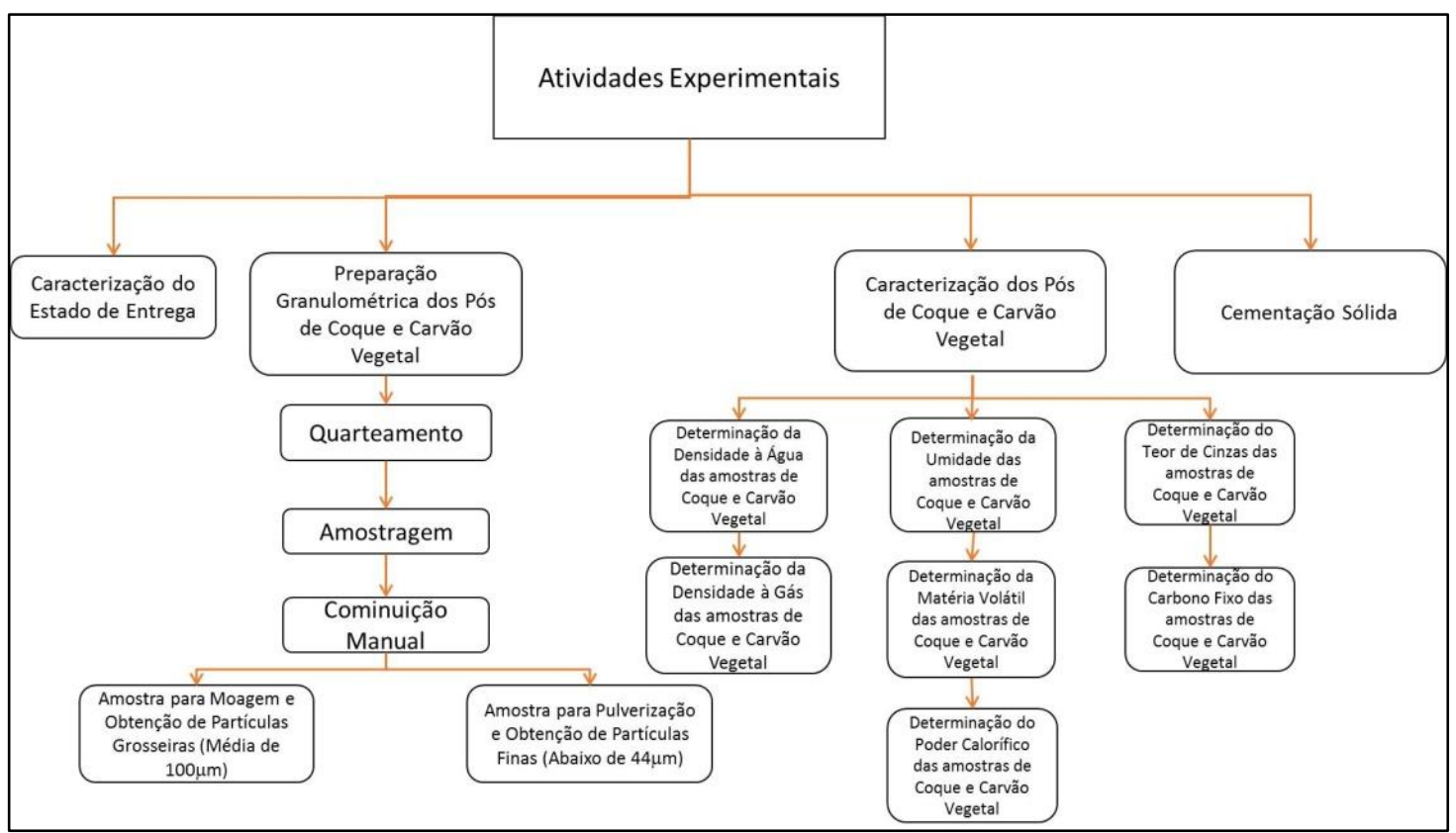

Figura 1.Fluxograma que resume as quatro principais etapas de desenvolvimento do trabalho.

$\mathrm{Na}$ caracterização do estado de entrega, as amostras de aço baixo carbono foram selecionadas e caracterizadas, química e microestruturalmente. As amostras foram quimicamente caracterizadas por meio da aplicação da técnica de espectrometria de emissão óptica, sendo utilizado um espectrômetro modelo Foundry-Master Xpert, do fabricante Oxford Instruments. Posteriormente, uma amostra com dimensões reduzidas, foi submetida a procedimentos padrão de preparação metalográfica, e imagens da microestrutura foram adquiridas em um microscópio óptico modelo DM2700 M do fabricante LEICA do Laboratório de Tratamentos Térmicos e Microscopia Óptica (LTM) do DEMET. As frações volumétricas de ferrita e perlita foram medidas por meio da aplicação de métodos de metalografia quantitativa padronizados.

A preparação granulométrica dos pós de coque e carvão vegetal foi realizada no Laboratório de Cerâmica e no Laboratório de Tratamentos de Minérios do 
Departamento de Engenharia de Minas (DEMIN-EM-UFOP). Foram executados procedimentos de cominuição (quarteamento até pulverização) e classificação granulométrica dos pós. Estas amostras, tanto de carvão vegetal quanto coque, foram classificadas com granulometria abaixo de $44 \mu \mathrm{m}$ (amostras pulverizadas), sendo utilizada peneira de abertura de 325\# da Série Tyler. Após essa etapa, foi feita a caracterização dos pós, que foi realizada seguindo normas padrões de química analítica (umidade, voláteis, cinzas, poder calorífico e carbono fixo).

A cementação sólida foi realizada no Laboratório de Tratamentos Térmicos e Microscopia Óptica (LTM) do DEMET-EM-UFOP. Amostras de aço baixo carbono foram colocadas em uma caixa fabricada em aço carbono, com uma divisão central, como pode ser observado na Figura 2. De um lado elas foram envolvidas por uma mistura que continha $30 \%$ de cal hidratada e $70 \%$ de carvão vegetal e do outro por $30 \%$ de cal hidratada e $70 \%$ de coque metalúrgico de baixa qualidade. Após esse procedimento, colocou-se todo o material em um forno tipo mufla à $1000^{\circ} \mathrm{C}$ durante 8 horas contínuas. Terminado este intervalo de tempo, o conjunto foi retirado e resfriado lentamente ao ar (taxas semelhantes à de um tratamento térmico de recozimento) até que as amostras pudessem ser seguramente retiradas.

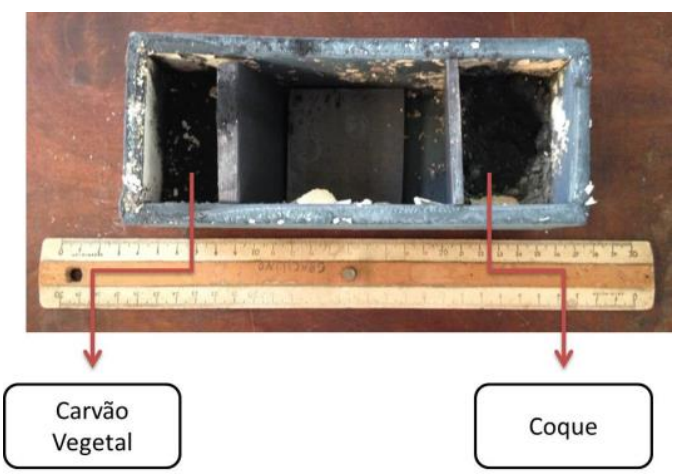

Figura 2.Caixa fabricada em aço carbono utilizada no tratamento termoquímico de Cementação Sólida.

As amostras cementadas em cada condição foram submetidas a procedimentos de corte refrigerado e cada uma deu origem a três amostras. As seis amostras resultantes foram submetidas a diferentes procedimentos, e foram numeradas de $1 \mathrm{a}$ 6 em função da rota a que foram submetidas. A Tabela 1 apresenta a relação entre a identificação das amostras e as condições de processamento. Posteriormente, cada uma das amostras foi microestruturalmente caracterizada por microscopia óptica e os perfis de microdureza Vickers foram determinados.

Tabela 1.Identificação das amostras e respectivas correspondências com as condições de tratamentos térmicos a que foram submetidas

\begin{tabular}{|l|l|l|l|}
\hline Amostras & Condições & Amostras & Condições \\
\hline 1 & $\begin{array}{l}\text { Amostra cementada em } \\
\text { carvão vegetal e recozida }\end{array}$ & 4 & $\begin{array}{l}\text { Amostra cementada em coque e } \\
\text { temperada em água. } \mathrm{T}=860^{\circ} \mathrm{C} \mid \\
\text { tencharque }=15 \text { min }\end{array}$ \\
\hline 3 & $\begin{array}{l}\text { Amostra cementada em } \\
\text { coque e recozida }\end{array}$ & 5 & $\begin{array}{l}\text { Amostra cementada em carvão } \\
\text { vegetal e temperada em água. } \\
\mathrm{T}=920^{\circ} \mathrm{C} \mid \text { tencharque }=15 \text { min }\end{array}$ \\
\hline & $\begin{array}{l}\text { Amostra cementada em } \\
\text { carvão vegetal e temperada } \\
\text { em água. } \mathrm{T}=860^{\circ} \mathrm{C} \mid \text { tencharque } \\
15 \text { min }\end{array}$ & 6 & $\begin{array}{l}\text { Amostra cementada em coque e } \\
\text { temperada em água. } \mathrm{T}=920^{\circ} \mathrm{C} \mid \\
\text { tencharque }=15 \text { min }\end{array}$ \\
\hline
\end{tabular}




\section{RESULTADOS E DISCUSSÃO}

\subsection{Caracterização do Estado de Entrega}

A Tabela 2 apresenta a composição química do aço estudado. Pode-se observar que se trata de um aço carbono comum com concentração de $\mathrm{C}$ de $0,14 \%$, $\mathrm{P}$ e $\mathrm{S}$ controlados. Não há significativa concentração de outros elementos de liga, o que permite assumir que se trata de um aço ABNT 1015 (NBR NM87).

Tabela 2.Composição química do aço estudado neste artigo (\% em massa)
\begin{tabular}{|l|l|l|l|l|l|l|}
\hline Composição Química (\% em massa) \\
\hline C & Mn & $\mathbf{P}$ & $\mathbf{S}$ & $\mathbf{S i}$ & $\mathbf{N i}$ & $\mathbf{C r}$ \\
\hline 0,14 & 0,50 & 0,016 & 0,024 & 0,12 & 0,036 & 0,058 \\
\hline Mo & $\mathbf{A l}$ & $\mathbf{C u}$ & $\mathbf{N}$ & $\mathbf{S n}$ & $\mathbf{C o}$ & $\mathbf{F e}$ \\
\hline 0.005 & 0,003 & 0,17 & 0,0073 & 0,0122 & 0,006 & 98,88 \\
\hline
\end{tabular}

A Figura 3 apresenta imagens da microestrutura do aço ABNT 1015 estudado neste trabalho no seu estado de entrega. Pode-se observar que se trata de uma estrutura constituída por ferrita primária e perlita. Para melhor caracterizar esta microestrutura, a metodologia $A_{A}$ de metalografia quantitativa para medição de fração volumétrica de microconstituintes foi empregada. Analisando 10 campos em um aumento de $500 x$, verificou-se que as frações volumétricas médias de ferrita e perlita foram, respectivamente, $(88 \pm 1) \%$ e $(12 \pm 1) \%$.

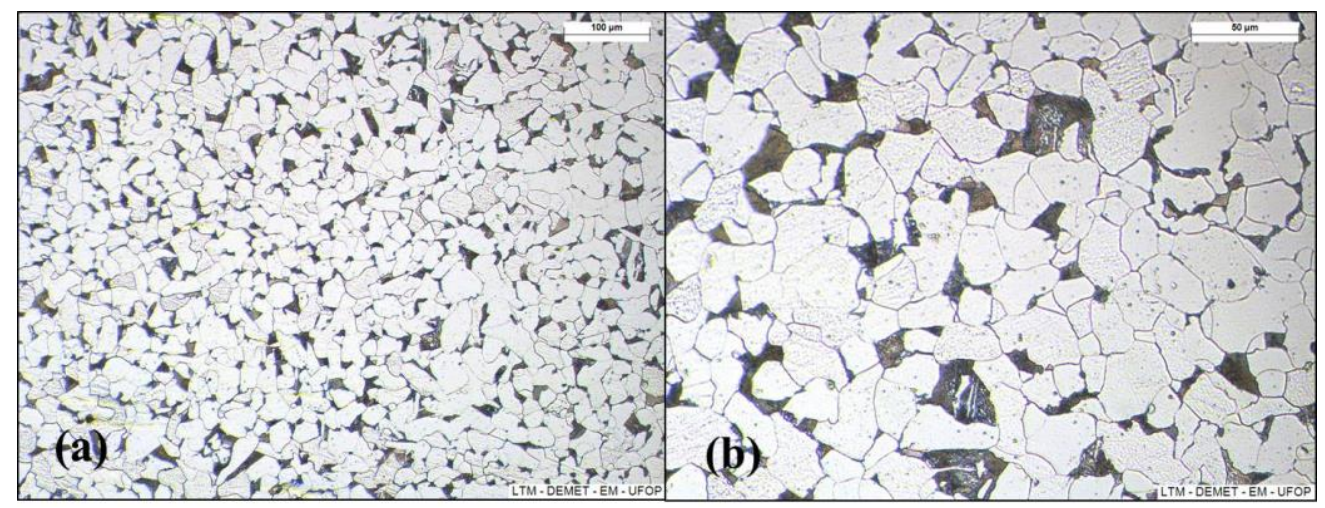

Figura 3.Microestrutura do aço ABNT 1015 no estado de entrega (a) 200x; (b) 500x - Nital 4\%.

\subsection{Caracterização dos Pós de Coque e Carvão Vegetal}

A Tabela 3 apresenta as principais características medidas para os pós de coque e carvão vegetal (fração pulverizada $<44 \mu \mathrm{m}$ ).

$\mathrm{Na}$ caracterização dos pós de carvão vegetal, os valores encontrados foram próximos dos dados que se tem acesso na literatura, com algumas pequenas variações. Essas diferenças ocorrem, pois, tipos de carvão vegetal são obtidos de diferentes tipos de madeira, sendo o Eucalyptus, o gêneromais comum. Os dados encontrados neste trabalho se assemelham aos encontrados por outros autores para as espécies Grandis e Urophylla [16,17].

$\mathrm{Na}$ caracterização dos pós de coque,verificou-se diferenças significativas na determinação do valor de poder calorífico, do carbono fixo e da porcentagem de cinzas em relação a valores típicos da literatura. O coque utilizado neste estudo 
apresentou valores de poder calorífico e carbono fixo muito inferiores e fração de cinzas muito levada, configurando-o como de baixa qualidade metalúrgica [18].

Tabela 3.Dados obtidos após caracterização dos pós de carvão vegetal e coque de baixa qualidade metalúrgica

\begin{tabular}{|l|l|l|}
\hline Caracterização & Carvão Vegetal & Coque \\
\hline Densidade por picnometria à água & 0,51 & 1,96 \\
\hline Densidade por picnometriaà gás & $(1,46 \pm 0,01) \mathrm{g} / \mathrm{cm}^{3}$ & $(1,94 \pm 0,01) \mathrm{g} / \mathrm{cm}^{3}$ \\
\hline Carbono Fixo & $(68,0 \pm 2,0) \%$ & $(54,0 \pm 0,4) \%$ \\
\hline Material Volátil & $(23,0 \pm 1,0) \%$ & $(3,42 \pm 0,05) \%$ \\
\hline Cinzas & $(1,8 \pm 0,4) \%$ & $(42,2 \pm 0,4) \%$ \\
\hline Poder Calorífico & $(7912 \pm 26) \mathrm{kcal} / \mathrm{kg}$ & $(4915 \pm 23) \mathrm{kcal} / \mathrm{kg}$ \\
\hline
\end{tabular}

Uma importante característica que influencia no processo de cementação é a superfície específica da fonte sólida de carbono. Sua definição é dada como a área superficial por unidade de massa de carvão vegetal ou coque. Em função da natureza do carvão vegetal (madeira carbonizada) e do processo de fabricação do coque, observa-se que a diferença de superfície específica entre os dois está diretamente associada à porosidade dos mesmos, como pode ser visto na Figura 4. O carvão vegetal, por apresentar maior superfície específica, possivelmente terá melhor desempenho na cementação, visto que se trata de um processo de difusão no estado sólido [19].

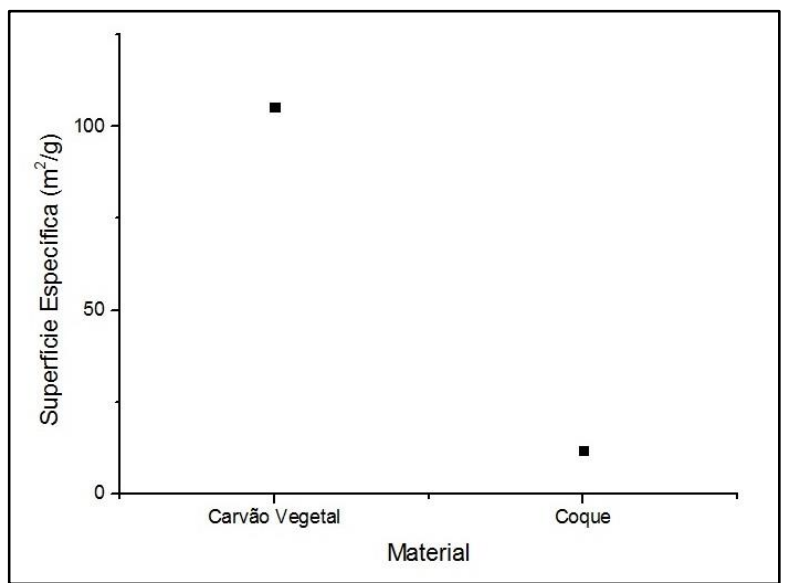

Figura 4.Superfície específica do carvão vegetal e do coque utilizados neste estudo. Dados obtidos pela técnica BET.

\subsection{Cementação Sólida}

\subsubsection{Caracterização das Amostras como Cementadas}

Neste tópico serão analisadas as amostras 1 e 2 (Figura 5). Como já apresentado, essas amostras não foram submetidas a tratamentos térmicos após a cementação sólida. 

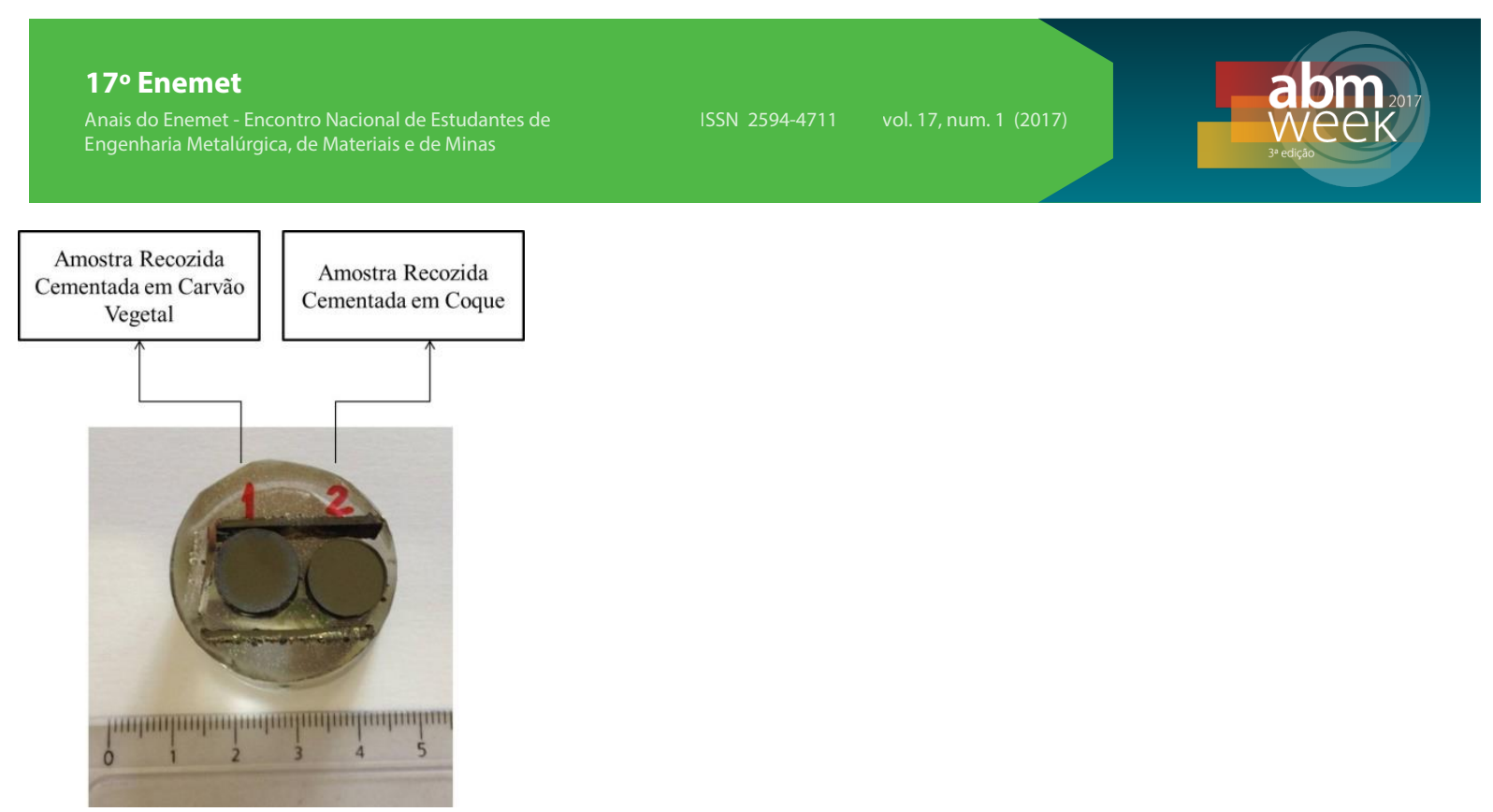

Figura 5.Macrografia das amostras cementadas com carvão vegetal e coque.

As Figuras 6 e 7 apresentam microestruturas da amostra 1 (carvão vegetal), e da amostra 2 (coque), respectivamente, ambas como cementadas. Destacam-se nas imagens três regiões principais, que são elas (a) Superfície; (b) Transição e (c) Centro. Observa-se que a cementação a carvão vegetal propiciou um resultado mais satisfatório quando comparada ao que foi alcançado na cementação com coque. Pelas microestruturas apresentadas, observa-se com clareza a diferença nas frações de perlita (região com coloração mais escura) e ferrita (região com coloração mais clara) na região cementada.

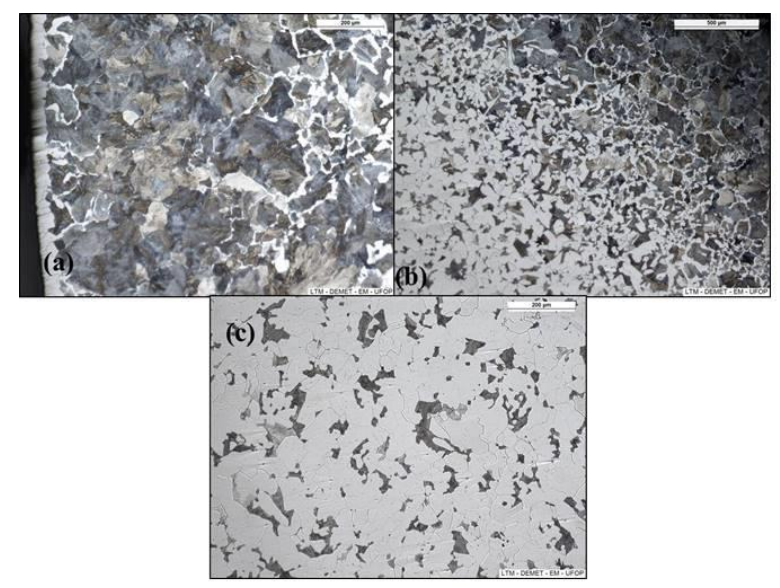

Figura 6.Microestrutura da amostra 1 cementada:(a) Superfície - 100x;

(b) Transição - 50x; (c) Centro - 100x.

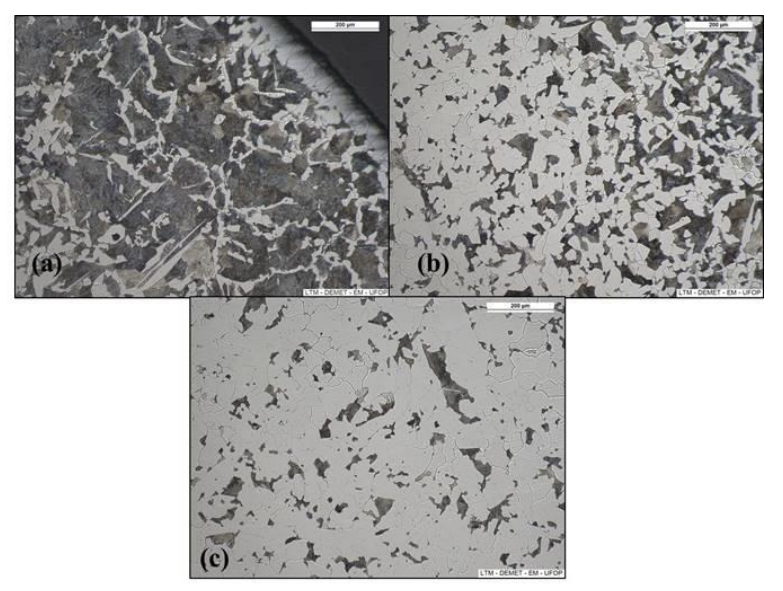

Figura 7.Microestrutura da amostra 2 cementada: (a) Superfície - 100x

b) Transição - 100x; (c) Centro - 100x.

Após a cementação, a fração de ferrita na superfície da amostra cementada com carvão passou a ser de $(9 \pm 1) \%$, e na cementada com coque, essa fração foi de $(33 \pm 9) \%$. Essa cementação irregular, possivelmente,se deve à baixa qualidade do coque utilizado. Como se mostrou na caracterização, esse coque possui baixo teor de carbono fixo, baixo poder calorífico e elevada fração de cinzas, o que levou a uma cementação irregular e insatisfatória.

\subsubsection{Efeito de Tratamentos Térmicos de Têmpera após as Cementações}

Como especificado em Materiais e Métodos, as amostras 3, 4, 5 e 6 foram submetidas a tratamentos térmicos de têmpera em água após o processo de 
cementação. As Figuras 8 e 9, apresentam as microestruturas da área de transição do núcleo para região cementada das amostras 3 e 4, respectivamente.

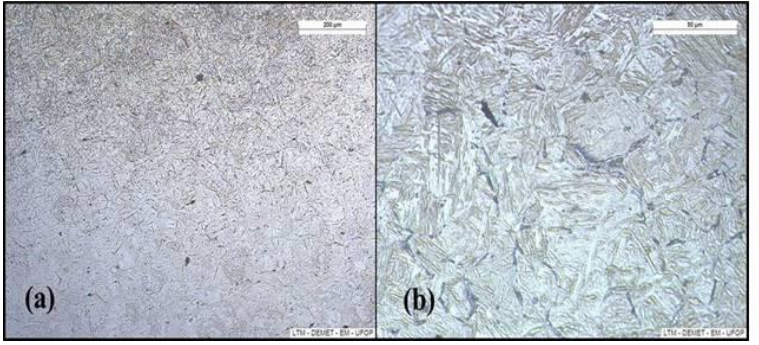

Figura 8.Microestrutura da amostra 3 cementada em carvão vegetal e temperada na região de transição

(a) 100x; (b) 500x.

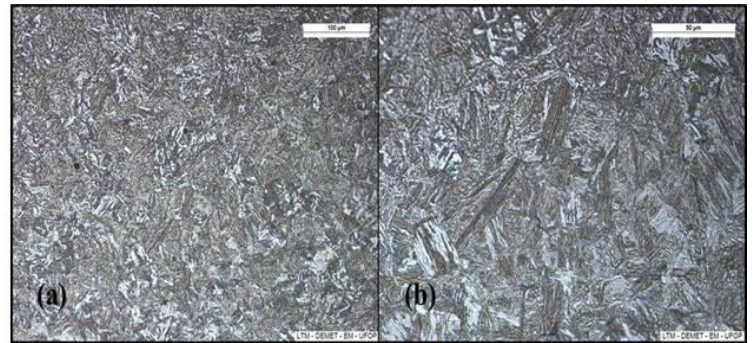

Figura 9.Microestrutura da amostra 4 cementada em coque e temperada na região de transição

(a) 200x; (b) 500x.

$\mathrm{Na}$ análise das amostras 3 e 4, que foram austenitizadas a $860^{\circ} \mathrm{C}$, observa-se uma microestrutura martensítica na camada cementada (superficial), observada nas Figuras 10 e 11. Pois nesta camada o teor de carbono aumentou e, certamente, a temperatura de $860^{\circ} \mathrm{C}$ está acima de $\mathrm{A} 3$, propiciando total austenitização da microestrutura nesta região que, quando temperada, teria temperabilidade suficiente para formar martensita.

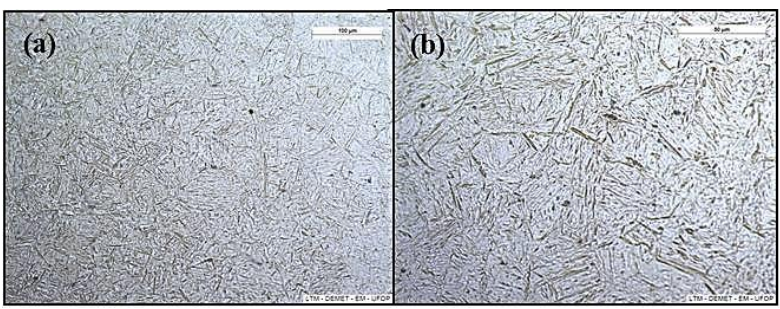

Figura 10.Microestrutura da amostra 3

cementada em carvão vegetal e temperada na região cementada - (a) 200x; (b) 500x.

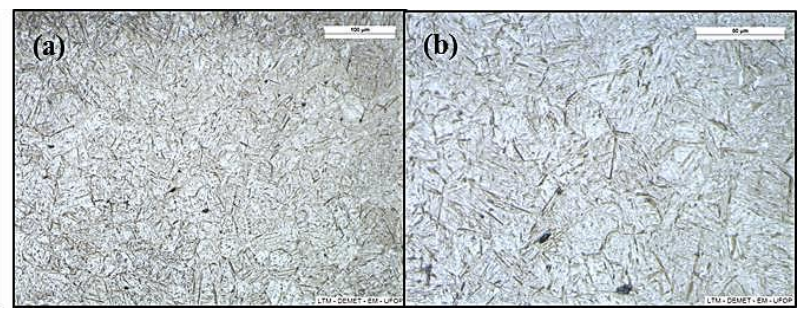

Figura 11.Microestrutura da amostra 4 cementadaem coque e temperada na região cementada- (a) 200x; (b) 500x.

Entretanto, as regiões centrais destas amostras, que possuem teor de carbono próximo de $0,14 \%$, foram apenas parcialmente austenitizadas, pois a temperatura de austenitização de aços com este teor de C está acima de $900^{\circ} \mathrm{C}$. Neste contexto, deve-se observar na região central uma microestrutura constituída por ferrita não dissolvida na austenitizaçao e bainita, como pode ser observado nas Figuras $12 \mathrm{e}$ $13[20]$.

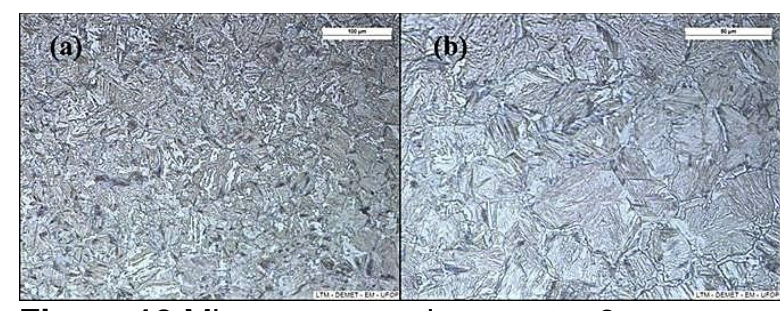

Figura 12.Microestrutura da amostra 3

cementada em carvão vegetal e temperada na região do núcleo - (a) 200x; (b) 500x.

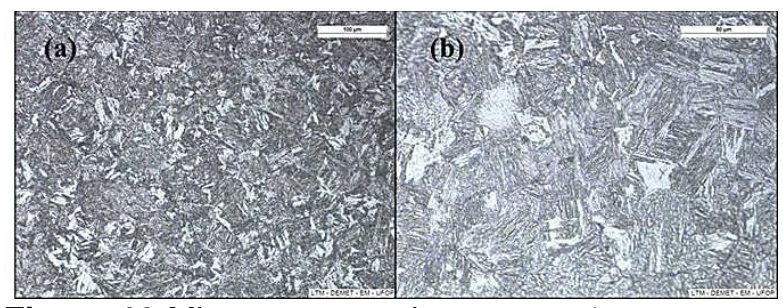

Figura 13.Microestrutura da amostra 4 cementada em coque e temperada na região do núcleo - (a) 200x; (b) 500x.

As Figuras 14 e 15 apresentam as microestruturas da área de transição do núcleo para região cementada das amostras 5 e 6, respectivamente. 




Figura 14.Microestrutura da amostra 5 cementada em carvão vegetal e temperada na região de transição - (a) 50x; (b) 100x.

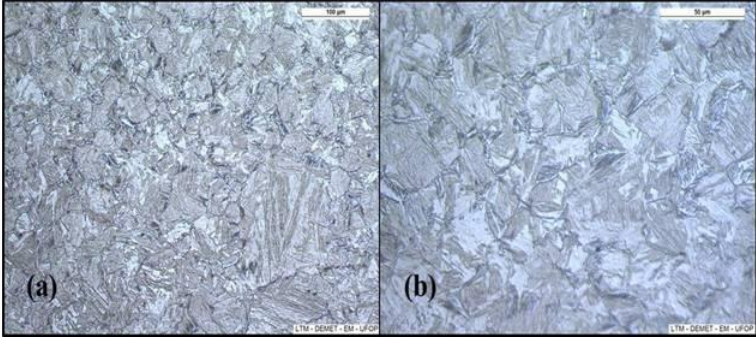

Figura 15.Microestrutura da amostra 6 cementada em coque e temperada na região de transição - (a) 200x; (b) 500x.

As amostras 5 e 6 foram austenitizadas, assim como as amostras 3 e 4 , porém em uma temperatura maior $\left(920^{\circ} \mathrm{C}\right)$, portanto acima de $\mathrm{A} 3$, mesmo para a região central das amostras. Desta forma, toda a ferrita foi austenitizada. Como consequência, obteve-se martensita nas superfícies cementadas e ferrita bainítica e bainita na região central.

A Figura 16 apresenta o comparativo de microdurezas Vickers entre as 6 amostras cementadas que foram submetidas aos diferentes processamentos estudados neste trabalho. $\mathrm{Na}$ análise das amostras 1 e 2, onde o objetivo foi apenas análise da cementação, verifica-se que houve um incremento da dureza na superfície das amostras em relação ao centro (em média 100HV).

Porémquando se aplica o tratamento térmico de têmpera percebe-se um aumento significativo desta diferença (em média evolui para $350 \mathrm{HV}$ ). Isto ocorre em decorrência da transformação martensítica na superfície cementada, como já verificado nas imagens de microscopia óptica. A dureza da região central das amostras cementadas e temperadas também se eleva em relação àquelas apenas cementadas. Isto se deve ao fato de que as amostras apenas cementadas, foram resfriadas muito lentamente (recozimento) quando comparadas às temperadas. Assim sendo, mesmo sendo o centro, uma região de baixa temperabilidade, há formação de ferrita bainítica e bainita nas amostras temperadas,conferindo a elas maior dureza. Nas amostras 1 e 2 a camada cementada efetiva apresentou espessura de até $1 \mathrm{~mm}$, enquanto nas outras amostras, essa espessura passa a ser de, aproximadamente, $1,75 \mathrm{~mm}$, ou seja, o tratamento de têmpera potencializa 0 efeito endurecedor da cementação.

Destaca-se ainda que tanto para as amostras apenas cementadas quanto para as amostras cementadas e temperadas, os valores de microdureza das amostras tratadas com coque sempre estão abaixo dos valores medidos daquelastratadas com carvão vegetal. Esta observação é mais um indicativo de que um menor enriquecimento em carbono foi alcançado com coque [21]. 


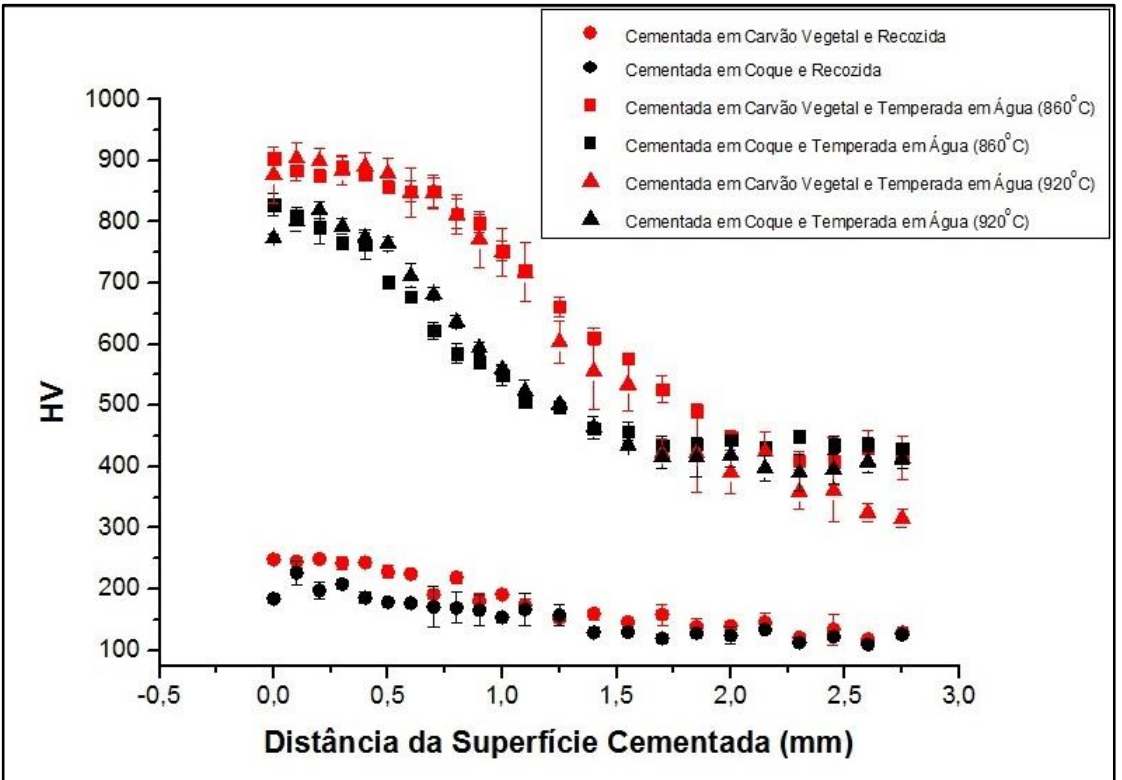

Figura 16.Comparativo entre os perfis de microdureza Vickers das amostras apenas cementadas e daquelas cementadas e temperadas.

\section{CONCLUSÃO}

Ostratamentos termoquímicos de cementação sólida avaliados foram eficientes e aumentaram consideravelmente a quantidade de carbono na superfície das peças analisadas, assim como a temperabilidade de suas superfícies e consequentemente suas capacidades de endurecimento.

Comparando-se os dois tipos de cementação avaliados, pôde-se concluir que o tratamento realizado com carvão vegetal foi o que apresentou melhores resultados, conferindo maior enriquecimento em carbono e cementação uniforme em todo 0 perímetro da peça.

A menor qualidade da cementação alcançada com o coque foi devido à sua baixa qualidade metalúrgica. Este coque possuía baixo poder calorífico, baixo carbono fixo e elevada concentração de cinzas quando comparado a coques metalúrgicos tradicionalmente utilizados em siderurgia.

Além da baixa qualidade metalúrgica do coque, outro fator que possivelmente favoreceu a cementação com carvão vegetal foi a sua baixa superfície específica quando comparada ao carvão.

\section{Agradecimentos}

Os autores agradecem a Fundação Gorceix pelo auxílio financeiro, ao Laboratório de Tratamentos Térmicos e Microscopia Óptica(LTM - DEMET/UFOP), ao Laboratório de Cerâmica e ao Laboratório de Tratamentos de Minérios (DEMIN-EMUFOP).

\section{REFERÊNCIAS}

1 ARAMID, F. O.; IBITOYE, S. A.; OLADELE, I. O.; BORODE, J. O. Pack Carburization of Mild Steel Using Pulverized Bone as Carburizer: Optimizing Process Parameters. EletronicJournalofPracticesandTechbologies. Vol.16. 2010.

2 DOSSET, J.L.; BOYLER, H.E. PracticalHeatTreating.Second Edition. 2006. 
3 ENNIS P. J.; LUPTON, D. F. The relationship Between Carburization and Ductility Loss, Behaviour of High Temperature Alloys in Aggressive Environments, In: Proceedings of the International Conference; 1979, Oct. 15-18, London: The Metals Society. 1980.

4 FAN-SHIONG ChenU, KUO-LIANG Wang. Super-carburization of low alloy steel and low carbono steel by fluidized-bed furnaces. Surface \& Coatings Technology. Vol.132. 2000.

5 GOLDSTEIN J. I.; MOREN A. E. Diffusion Modeling of the Carburization Process. Metallurgical and Materials Transactions A. 9 (11). 1978.

6 GOROCKIEWICZ R. The kinetics of low-pressure carburizing of alloy steels. Vaccum. Vol.86. 2011.

7 LEITÃO, C. J. Efeito da Nitretação e da Cementação na Deformação de Peças de Aços Carbono e Baixa Liga. Dissertação de Mestrado - Universidade Estadual de Campinas, 2010.

8 LOGUERCIO, J. F. C. Desenvolvimento de um Aço SAE 5115 Microligado ao Nióbio Para Cementação a Alta Temperatura. Dissertação de Mestrado - PPGEM. 2003.

9 MALINOV, L. S.; KHARLASHKIN, V. A. Effect of Cementation and Heat Treatment of Steel 10Г12 on Metastable Austenite in the Structure, Abrasive and Impact Wear Resistance. Metal Science \&HeatTreatment. Vol. 3, No. 2. 2011.

$10 \mathrm{MEI}$, P. R.; SILVA, A. L. C. e. Aços e Ligas Especiais. 3ª Edição. 2011.

11 MITTEMEIJER, E. J.; SOMERS M. A. J. Thermochemical Surface Engineering of steels: Improving Materials Performance. 2014.

12 NAKAYAMA K.; An Overview of the Excess Carburizing Process. Int. J. Mater. Prod. Technol. 1992.

13 OYETUNJI, A.; ADEOSUN, S.O. Effects of Carburizing Process Variables on Mechanical and Chemical Properties of Carburized Mild Steel. Journal of Basic \& Applied Sciences. Vol.8. 2012.

14 SCHEUER, C. J. Cementação a Baixa Temperatura do Aço Inoxidável Martensítico AISI 420 Assistida Por Plasma. Dissertação de Mestrado - Universidade Federal do Paraná. 2011.

15 ZAJUSZ, M.; TKACZ-ŚMIECH K.; DANIELEWSKI, M. Modeling of vacum pulse carburizing of steel. Surface\&Coatings Technology. Vol.258. 2014.

16 PEREIRA, José Carlos Duarte et al. Características da madeira de algumas espécies de eucalipto plantadas no Brasil [página da internet]. Colombo, Paraná. Embrapa Florestas, 2000. 113p. [acesso em 30 de maio de 2016]. Disponível em: http://ainfo.cnptia.embrapa.br/digital/bitstream/item/94756/1/doc38.pdf.

17 OLIVEIRA, Alison Costa. Parâmetros de Qualidade da Madeira e do Carvão Vegetal de Eucalyptus Pellita. Science Forum. Vol.38. 431-439. 2010.

18 PETRO - Energia Industrial - Coque [página da internet] [acesso em 22 de junho de 2016]. Disponível em: http://www.petroenergia.com.br/coque.html.

19 YALLICO, Yovanna Gisela Palomares. Reatividade Comparativa de Coque, Carvão mineral, Carvão Vegetal e Coque Verde de Petróleo [página da internet]. Dissertação de Mestrado. Pontifícia Universidade Católica do Rio de Janeiro. Rio de Janeiro, 2011 [acesso em 25 de maio de 2016]. Disponível em: http://www.maxwell.vrac.pucrio.br/19428/19428 4.PDF.

20 CIÊNCIA DOS MATERIAIS MULTIMÍDIA. Capítulo 16 - Mudança de Estrutura Tópico 16.21. Martensita [página da internet] [acesso em 04 de junho de 2016]. Disponível em: http://www.cienciadosmateriais.org/index.php?acao=exibir\&cap=21\&top=140.

21 CHIAVERINI, V. Tecnologia Mecânica - Materiais de Construção Mecânica. São Paulo, 2ª Edição, Volume III. McGraw-Hill, 1986. 